\title{
Considering statins for cholesterol-reduction in children if lifestyle and diet changes do not improve their health: a review of the risks and benefits
}

\author{
This article was published in the following Dove Press journal: \\ Vascular Health and Risk Management \\ 17 December 2010 \\ Number of times this article has been viewed
}

\section{Clodagh SM O'Gorman' \\ Michael B O'Neill ${ }^{2}$ \\ Louise S Conwell ${ }^{3}$}

'Graduate Entry Medical School, University of Limerick, Ireland, and Mid-Western Regional Hospital, Limerick, Ireland; ${ }^{2}$ Mayo General Hospital, Castlebar, Ireland; ${ }^{3}$ Royal Children's Hospital, Brisbane, Discipline of Pediatrics and Child Health, and School of Medicine, University of Queensland, Brisbane, Australia
Correspondence: Clodagh O'Gorman Professor of Pediatrics, Graduate Entry Medical School, University of Limerick, Limerick, Ireland

Fax 0 II 353 6I 482498

Email clodagh.ogorman@ul.ie

\begin{abstract}
Children who appear healthy, even if they have one or more recognized cardiovascular risk factors, do not generally have outcomes of cardiovascular or other vascular disease during childhood. Historically, pediatric medicine has not aggressively screened for or treated cardiovascular risk factors in otherwise healthy children. However, studies such as the P-Day Study (Pathobiological Determinants of Atherosclerosis in Youth), and the Bogalusa Heart Study, indicate that healthy children at remarkably young ages can have evidence of significant atherosclerosis. With the increasing prevalence of pediatric obesity, can we expect more health problems related to the consequences of pediatric dyslipidemia, hypertriglyceridemia, and atherosclerosis in the future? For many years, medications have been available and used in adult populations to treat dyslipidemia. In recent years, reports of short-term safety of some of these medications in children have been published. However, none of these studies have detailed long-term follow-up, and therefore none have described potential late side-effects of early cholesterol-lowering therapy, or potential benefits in terms of reduction of or delay in cardiovascular or other vascular end-points. In 2007, the American Heart Association published a scientific statement on the use of cholesterol-lowering therapy in pediatric patients. In this review paper, we discuss some of the current literature on cholesterol-lowering therapy in children, including the statins that are currently available for use in children, and some of the cautions with using these and other cholesterol-lowering medications. A central tenet of this review is that medications are not a substitute for dietary and lifestyle interventions, and that even in children on cholesterol-lowering medications, physicians should take every opportunity to encourage children and their parents to make healthy diet and lifestyle choices.
\end{abstract}

Keywords: cholesterol, statins, children, adolescents, vascular risk

\section{Background}

In 1961, atherosclerosis was described by Holman as "a pediatric problem", 1 recognizing that atherosclerosis, associated typically with adults, has its origins in the pediatric age range. The P-Day Study, or Pathobiological Determinants of Atherosclerosis in Youth Study, is a multi-center postmortem study in youth, 15 to 34 years old, following death by trauma, homicide, or suicide, ${ }^{2}$ where traditional cardiovascular risk factors were estimated in the 48 hours following death. This study demonstrated conclusively that cardiovascular risk factors such as hypercholesterolemia and hypertension were associated with the size of arterial fatty streaks and fibrous plaques in youth. ${ }^{2,3}$ Prior to this landmark study, postmortem studies of young soldiers during the Korean 
war ${ }^{4}$ and the Vietnam war ${ }^{5}$ found postmortem evidence of atherosclerosis in youth who had been perceived to be healthy before sudden death during war. During the Vietnam war specifically, of 105 soldiers who died, at a mean age of 22 years, $45 \%$ and $5 \%$ of soldiers had gross evidence of some or severe coronary atherosclerosis, respectively. ${ }^{5}$ The Bogalusa Heart Study included both epidemiological and opportunistic pathological studies, and found that both coronary and aortic fatty streaks in 35 autopsied subjects were positively associated with low-density lipoprotein cholesterol (LDLc) and negatively associated with high-density lipoprotein cholesterol (HDLc) measured during life. ${ }^{6}$ In its pathological study, the Bogalusa investigators found that the prevalence of fatty streaks and fibrous plaques were $50 \%$ and $8 \%$, respectively, during childhood, and $69 \%$ and $85 \%$, respectively, during young adulthood. ${ }^{7}$ Thus, these studies have supported Holman's claim, ${ }^{1}$ that atherosclerosis can begin in childhood.

While pathology studies are important and have yielded much valuable information, identifying early evidence of atherosclerosis and vascular disease in vivo, in children at young ages, before the end-points of atherosclerosis manifest is a preferred strategy. Ultrasound may be used, in a standardized manner, to assess the thickness of the carotid intima-media layer, as this thickness is positively associated with various cardiac risk factors, ${ }^{8}$ as well as with clusters of risk factors. ${ }^{9}$ Ultrasound can also be used to assess arterial function, including distensibility, stiffness, and vasodilation. Children with familial hypercholesterolemia have increased carotid artery stiffness, independent of their blood pressure. ${ }^{10}$ Impaired fitness and overweight are associated with vascular dysfunction, ${ }^{11}$ which, in turn, in the obese population is associated with decreased insulin sensitivity ${ }^{12}$ and vascular dysfunction. ${ }^{13}$ Additionally, children with type 1 diabetes mellitus have been shown to have vascular dysfunction using several different measures of vascular function, ${ }^{14,15}$ including pulse wave velocity. ${ }^{16}$ Identifying a positive family history of early ischemic heart disease, without additional known risk factors in children, is associated with impaired vascular function in children. ${ }^{10}$ For adults, the results of the Framingham heart study have led to the development of the Framingham risk score, which can be used to cumulate an individual's risk factors, and predict that individual's risk of developing ischemic heart disease over time. Recently, a not dissimilar risk score was developed for pediatric patients. ${ }^{17}$ This tool accurately predicts advanced atherosclerotic lesions noted at autopsy. Further clinical and epidemiological studies are required for validation, but it may prove a useful tool for screening, treating, communicating with patients, and translating risks for individual patients.

In the last 3 decades, the incidence of pediatric obesity in the USA has tripled. Furthermore, the TODAY Study (Treatment Options for type 2 Diabetes in Adolescents and Youth Study) suggests that, of type 2 diabetes mellitus pediatric patients, who are obese at presentation, up to $60 \%$ have dyslipidemia, and $17 \%$ have hypertension at presentation. ${ }^{18}$ It is worth noting that hypertriglyceridemia is the dyslipidemia primarily associated with obesity. When Holman described atherosclerosis as a pediatric problem, ${ }^{1}$ he referred largely to children with primary, or monogenic, causes of hypercholesterolemia - children with conditions such as familial hypercholesterolemia. Currently, the numbers of children with hypercholesterolemia reflect largely an increase in those with secondary hypercholesterolemia, especially hyperlipidemia secondary to obesity. ${ }^{19}$ This reflects a paradigm shift in the etiology of hypercholesterolemia in children and adolescents. But has there been a parallel paradigm shift in our approach to therapy in these children?

\section{Principles of medication use in children with dyslipidemia}

The initiation of cholesterol-lowering therapy, as with any new therapy, in an individual patient should be accompanied by knowledge of the desired end-point or surrogate marker of that end-point, ie, reduction in cholesterol or reduction in cardiovascular or vascular disease events. For cholesterollowering, there are recommended levels of cholesterol to aim for when starting cholesterol-lowering therapies. ${ }^{19}$ Dyslipidemia is a recognized risk factor for cardiovascular and vascular disease, and has a recognized role in the pathophysiology of cardiovascular and vascular disease. However, the final end-points of vascular and cardiovascular disease are rarely seen in normal childhood, and so, in pediatrics, surrogate markers are required to replace these end-points. Evidence supports the role of statins in both primary and secondary prevention of ischemic heart disease in adult patients, and this evidence has been extrapolated from adult studies to pediatric patients. The longest duration of follow-up in the studies of statins in children is only 2 years. ${ }^{20}$ Studies in pediatric populations demonstrate an improvement in vascular function with statin therapy in children with heterozygous familial hypercholesterolemia (heFH). One such study demonstrated an improvement in flow-mediated dilatation with 28 weeks of simvastatin therapy. ${ }^{21}$ Another study demonstrated an improvement in carotid intima-media thickness (CIMT) with 2 years of 
pravastatin therapy. ${ }^{20}$ Both studied pediatric patients with familial hypercholesterolemia. But, flow-mediated dilatation and CIMT are only surrogate markers for atherosclerosis. Unless we support large multi-center randomized controlled trials (RCTs), with long-term follow-up, we may never have data on the efficacy of our pediatric vascular disease prevention measures when our patients reach adulthood. If we continue to start statins, and other cholesterol-lowering therapy, in children, without long-term evidence of vascular disease prevention, we may never be able to gather this evidence. However, given the evidence we have to date on the likelihood of vascular disease prevention, in high-risk patients, such as those with heFH, it is probably unethical to withhold therapy from these children. In this case, long-term epidemiological studies are required to gather evidence.

In 2007, the American Heart Association (AHA) published a scientific statement on the drug therapy of high-risk lipid abnormalities in children and adolescents, ${ }^{19}$ recommending drug therapy for high-risk lipid abnormalities in children as young as 8 years old, and specifically starting therapy with a statin medication. This sparked discussion in the pediatric medical community on the potential risks and benefits of statin therapy in children. Subsequently, the AHA statement was endorsed by the American Academy of Pediatrics (AAP). ${ }^{22}$

There is mounting evidence of truth in Holman's words, that atherosclerosis is "a pediatric problem". ${ }^{1}$ It appears that this truth is even truer today, with our current and increasing problems with pediatric obesity, while acknowledging that our clinical end-points for treating hyperlipidemia in children are limited by the fact that our patients are children. This invited review aims to describe the current options and controversies in the pharmacological therapies available for pediatric hyperlipidemia.

\section{Primary versus secondary hyperlipidemia and high-risk conditions}

Hyperlipidemia may be primary, when it occurs as a main feature of the primary disease causing hyperlipidemia, or secondary, when it occurs as a consequence of a related disease, disorder, or treatment. Primary hyperlipidemia may occur in children with genetic conditions that cause hyperlipidemia. Examples of these include homozygous familial hypercholesterolemia (hoFH) and heFH, familial hypertriglyceridemia, familial combined hyperlipidemia, and dysbetalipoproteinemia. It is worth noting that some of these causes of primary hyperlipidemia only manifest in childhood if driven by obesity and/or diabetes. They may therefore, in fact, be seen as secondary lipid disorders when they occur in childhood. In fact, at any step in the pathway to synthesis of cholesterol, a mutation may result in dyslipidemia. ${ }^{23}$ Studies on populations of children with heFH comprise a significant proportion of data available on the treatment and results of cholesterol-lowering in pediatric age patients.

The prevalence of secondary hyperlipidemia, or hyperlipidemia or dyslipidemia occurring as a consequence of a disease, disorder, or therapy has increased significantly in recent years, as the prevalence of the related diseases, disorders, and therapies has increased. Examples of diseases and disorders associated with dyslipidemia include diabetes mellitus (both type 1 and type 2), renal failure, hypothyroidism, and liver failure. Examples of medications that predispose to dyslipidemia include glucocorticoids, retinoids (for example, for use in patients with acne), beta-blockers, and anti-retroviral therapies. ${ }^{24}$ In recent years, arguably the single biggest contributor to the increased prevalence of dyslipidemia is the increase in childhood obesity, with complications, including the metabolic syndrome and with hypertrygliceridemia as the specific lipid abnormality associated with insulin resistance. In one recent study, predefined cutoffs for abnormal LDLc levels were applied to almost 10,000 children from the NHANES (National Health and Nutrition Examination Survey) $1999-2006$ cohort, and $5.2 \%$ to $6.6 \%$ of included adolescents had abnormal LDLc levels. ${ }^{25}$

With many possible etiologies for dyslipidemia, it makes sense that clinicians should exercise caution when interpreting the results of cholesterol-lowering therapy in one population of patients, prior to assuming these same results might or would apply to another population of patients.

The AHA $2007^{19}$ statement suggested that some conditions should be regarded as high-risk conditions, and that if a child with a high-risk condition has hyperlipidemia, that prompt treatment with pharmacological therapy should be considered. The definitions of hyperlipidemia are given in the AHA statement. ${ }^{19}$ Examples of these high-risk conditions include:

- Male gender;

- Strong family history of early vascular or cardiovascular disease;

- Low HDLc, high triglycerides (TG), and high small dense LDLc;

- Overweight or obesity, and other components of the metabolic syndrome;

- Simultaneous diagnosis of other conditions, for example, diabetes, hypertension, survivors of childhood cancer, 
diabetes, HIV infection, history of organ transplantation, and systemic lupus erythrematosus;

- Smoking, or passive exposure to smoke;

- Simultaneous presence of newer risk factors or markers for vascular and cardiovascular disease, including increased lipoprotein (a), homocysteine, C-reactive protein.

The AHA recommends considering starting therapy after the age of 10 years, and after Tanner II puberty in males, or after 10 years and after menarche in females. However, for children who are considered high risk, and who fulfill the above criteria, the AHA recommends considering starting therapy after the age of 8 years rather than after the age of 10 years. $^{19}$

\section{Screening for hyperlipidemia: universal versus targeted screening}

The AHA $2007^{19}$ position statement endorses targeted, as opposed to universal, screening for hyperlipidemia, citing that children with hyperlipidemia, who do not have a family history of early cardiovascular disease are considered to be at low risk, and therefore should probably not start medications for hyperlipidemia until at least adulthood. Therefore, targeted screening was recommended for children with any of:

1. A family history of parental or grand-parental vascular disease at less than 55 years of age. Vascular diseases cited include coronary artery disease, peripheral vascular disease, cerebrovascular disease, a coronary artery procedure, myocardial infarction, or sudden cardiac death;

2. A family history of increased total cholesterol $(>6.2 \mathrm{mmol} / \mathrm{L})$. The recommendation is that these children should be screened with fasting total cholesterol measurements;

3. Overweight or obesity. If hyperlipidemia is identified, these children should then also be screened for other elements of the metabolic syndrome.

In 1998, the AAP published recommendations on screening for hypercholesterolemia in children. ${ }^{26}$ Failure to identify accurately parental history of hypercholesterolemia or cardiovascular disease may result in inappropriate screening and poor results for targeted screening. Targeting children of parents with premature vascular disease may be more effective. One such study identified parents who had early (ie, at less than 55 years old) myocardial infarctions, and were attending cardiovascular rehabilitation for secondary prevention. The authors found prevalences of $7 / 82(8.5 \%)$ and $17 / 82(20.7 \%)$ for high $(>3.35 \mathrm{mmol} / \mathrm{L}$, or $>130 \mathrm{mg} / \mathrm{dL})$ and borderline-high $(>2.85 \mathrm{mmol} / \mathrm{L}$, or
$>130 \mathrm{mg} / \mathrm{dL}$ ) LDLc respectively. ${ }^{27}$ In 2010 , the CARDIAC project results of a study on over 20,000 children suggested that universal screening is better than targeted screening. ${ }^{28}$ It identified that $28.6 \%$ of its study population did not meet National Cholesterol Education Program Expert Panel on Blood Cholesterol Levels in Children and Adolescents (NCEP) screening guidelines for dyslipidemia, but, of these, $9.5 \%(\mathrm{~N}=548)$ had dyslipidemia and $1.7 \%(\mathrm{~N}=98)$ required therapy for dyslipidemia. It is possible that the better results were due to poor selection of children for targeted screening in other studies. Nonetheless, on balance, these studies suggest that targeted screening for pediatric dyslipidemia misses some children at risk, and clinicians should be aware of this.

The AAP published new recommendations on screening for pediatric hyperlipidemia in 2008, ${ }^{22}$ following the AHA statement published in 2007. ${ }^{19}$ These new AAP recommendations suggest that targeted screening for hyperlipidemia in children should be performed using a full fasting lipid profile every 3 to 5 years, beginning at age 2 years, using age and gender-specific norms for interpreting results (and considering results $>95$ th percentile as abnormal). The triggers for initiating targeted screening include:

1. a positive family history of early atherosclerosis;

2. a positive family history of high cholesterol;

3. an unknown family history;

4. taking into consideration other risk factors individual to the child.

The first 2 recommendations for targeted screening endorse the AHA statement. ${ }^{19}$ The remainder of the recommendations provides some clarity in unknown circumstances, and accounts for the child without a family history.

\section{Therapeutic options}

This review paper addresses pharmacological therapeutic options, after diet and exercise have failed, but healthy diet and lifestyle choices must be "prescribed", encouraged, and reinforced constantly, concurrent with pharmacological therapy. Additionally, both dietary and lifestyle modifications should be undertaken by the entire family, and not just by the index pediatric case. As with all adolescent medical encounters, the opportunity should also be taken to encourage avoidance of cigarette smoking and alcohol consumption, and use of contraception. The latter is especially true if cholesterol-lowering pharmacological interventions are being considered or prescribed, due to potential teratogenicity. While we believe that they may have added value, a discussion of the potential benefits of 
nonpharmacological substances, ie, nutraceuticals, such as plant sterols and psyllium, is beyond the scope of this text. Finally, particularly with the recognized increase in dyslipidemia secondary to obesity, clinicians need to be particularly aware of the need to treat the primary cause of dyslipidemia, ie, weight reduction for obesity.

\section{Therapeutic options: diet}

Firstly, as with all pediatric dietary interventions, dietary modifications for dyslipidemia must be instituted for the entire family, and therefore for the child in the context of family therapy. For high-risk individuals, and for motivated low-risk individuals, recommended dietary guidelines include a balanced caloric intake, a diet high in wholegrains, fish, fruit, and vegetables, low in salt and sugar-added products, and choosing low-fat dairy produce - a so-called "heart-healthy" diet. Individuals with secondary dyslipidemia may benefit significantly from such dietary guidelines, even more so than individuals with primary, or monogenic, hypercholesterolemia. ${ }^{24}$ However, these guidelines should be shared with all patients and their parents, and both parties encouraged to follow them together. The debate on statin therapy, and the safe age at which to start therapy for dyslipidemia, is ongoing. ${ }^{29,30}$ With this in mind, following guidelines such as these may be of particular importance and benefit to younger patients with dyslipidemia, in whom there are more concerns about the safety of statin therapy. The AHA has new dietary guidelines, called the Therapeutic Lifestyle Changes (TLCs), which summarize and are based on the above principles, and which replace the previous Step I and Step II diets. The pediatric-specific information on these new dietary guidelines was published in $2005,{ }^{31}$ and was subsequently endorsed by the AAP. ${ }^{32}$ Full information for parents and pediatricians is available on the AHA website. ${ }^{33}$

The 2008 AAP position statement by the AAP Committee on Nutrition ${ }^{22}$ included guidelines on diet for dyslipidemia, and these were expanded based on the previous 1998 AAP guidelines. ${ }^{26}$ The pertinent changes in the new guidelines include:

1. initiation of nutritional therapy, with low-fat milk products, at age 1 year in children at risk due to obesity or family history of obesity-related complications;

2. saturated fat and trans fat to comprise $<7 \%$ and $<1 \%$ of the daily dietary caloric intake, respectively;

3. dietary cholesterol intake limited to $<200 \mathrm{mg} /$ day;

4. fiber intake recommended to be at least equal to the child's age in years, plus 5, up to $20 \mathrm{~g}$ /day. (For example, a 2-year-old child's fiber intake should be $7 \mathrm{~g} /$ day minimum; a 7 year old's should be 12 g/day minimum; and from the age of 15 years, fiber intake should be $20 \mathrm{~g} /$ day.)

A more exhaustive comparison between these guidelines is given in Table $1 .^{30}$

Notwithstanding the ability of a heart-healthy diet to reduce cholesterol levels, it has not been proven that dietary treatment in childhood reduces atherosclerosis, and vascular and cardiovascular disease in adult life. ${ }^{34}$ However, this systematic review and meta-analysis was based on published and unpublished RCTs of dietary intervention in pediatric patients with familial hypercholesterolemia. Again, it is not necessarily true that the data from this study can be extrapolated to patients with secondary dyslipidemia, or dyslipidemia from other etiologies. Further studies, in other patient populations, are required. In the interim, care must be exercised, and heart-healthy diets should be recommended to high-risk patients. Following a low-fat diet is recommended from the age of 1 year in at-risk patients. ${ }^{22}$ Heart-healthy diets may confer benefits beyond cholesterol reduction, for example caloric reduction may help with weight loss and improve insulin sensitivity, and salt reduction may improve control of blood pressure.

\section{Therapeutic options: lifestyle}

Similar to dietary changes, lifestyle changes must be instituted for the entire family, and therefore for the child in the context of family therapy. Data from adult studies demonstrate clinically relevant improvements in cholesterol, and other measures, following intensive combined exercise programs and dietary education and guidelines. Improvements in cholesterol, blood pressure, weight, and various other measures contribute to improved vascular risk profiles in adults. Some similar data exist in pediatric populations ${ }^{35}$ leading to a recommendation of tailored exercise programs for children. Further data to substantiate this recommendation are required. Specific recommendations from the AAP include: 1) limiting screen time (including television, computer, game screen time) to 120 minutes per day for all children more than 2 years old; ${ }^{36}$ and 2 ) no screen time for all children less than 2 years old. ${ }^{36}$ The 2008 Committee on Nutrition AAP statement recommends that physical activity should be encouraged, specifically as a treatment for weight management, for hypertriglceridemia, and for low HDLc. ${ }^{22}$ The initial purpose of limiting screen time was to protect neurocognitive development, but another advantage 
Table I Comparison of AAP Recommendations on Hypercholesterolmia in 1998 and 2008

\begin{tabular}{|c|c|c|}
\hline Recommendation & 1998 & 2008 \\
\hline \multicolumn{3}{|l|}{ Screening } \\
\hline & $\begin{array}{l}\text { Measure nonfasting total cholesterol or fasting } \\
\text { lipids according to algorithm }\end{array}$ & Assess fasting lipid profile \\
\hline & $\begin{array}{l}\text { Recommended with family history of high } \\
\text { cholesterol or early atherosclerosis }\end{array}$ & (Unchanged) \\
\hline & Optional with unknown family history & Recommended with unknown family history \\
\hline & Optional given personal risk factors & $\begin{array}{l}\text { Recommended given personal risk factors. Screen } \\
\text { every } 3-5 \mathrm{yr} \text { beginning at } 2 \mathrm{yr} \text { of age }\end{array}$ \\
\hline & $\begin{array}{l}\text { Use same cutoff point? for all ages } \\
\text { and both sexes }\end{array}$ & $\begin{array}{l}\text { Use age- and sex-specific cholesterol norms } \\
\text { (>95th percentile considered abnormal) }\end{array}$ \\
\hline & $\begin{array}{l}\text { No specific recommendations for high } \\
\text { triglyceride levels and low HDL cholesterol levels }\end{array}$ & $\begin{array}{l}\text { Measure triglyceride and HDL cholesterol levels, } \\
\text { with age- and sex-specific norms }\end{array}$ \\
\hline \multicolumn{3}{|l|}{ Diet and exercise } \\
\hline & Begin nutritional therapy at $2 \mathrm{yr}$ of age & $\begin{array}{l}\text { Begin nutritional therapy with reduced-fat milk at } \\
\text { I yr for children at risk owing to obesity or family }\end{array}$ \\
\hline & $\begin{array}{l}\text { Initiate treatment with NCEP Step-One Diet } \\
\text { (total fat } 20 \text { to } 30 \% \text { of total calories consumed, } \\
\text { saturated fat }<10 \% \text {, dietary cholesterol }<300 \mathrm{mg} / \text { day); } \\
\text { if diet is not effective after } 3 \mathrm{mo} \text {, progress to Step-Two } \\
\text { Diet: (total fat } 20 \text { to } 30 \% \text {, saturated fat }<7 \% \text {, dietary } \\
\text { cholesterol }<200 \mathrm{mg} / \text { day] }\end{array}$ & $\begin{array}{l}\text { Follow Dietary Guidelines for Americans, } \\
\text { with saturated fat }<7 \% \text {, trans fat }<1 \% \text {, dietary } \\
\text { cholesterol }<200 \mathrm{mg} / \text { day, and suggested fiber } \\
\text { intake equal to child's age plus } 5 \mathrm{~g} / \text { day, up to } 20 \\
\mathrm{~g} / \text { day at } 15 \mathrm{yr} \text { of age }\end{array}$ \\
\hline & Encourage regular exercise & $\begin{array}{l}\text { Encourage physical activity for weight } \\
\text { management and for treatment of high } \\
\text { triglyceride levels and low HDL cholesterol levels }\end{array}$ \\
\hline \multicolumn{3}{|l|}{ Pharmacology } \\
\hline & $\begin{array}{l}\text { Use bile acid-binding agents as first-line agent; } \\
\text { stations not recommended }\end{array}$ & Include statins among potential first-line agents \\
\hline & I0-yr minimum age for pharmacotherapy & 8-yr minimum age for pharmacotherapy \\
\hline & $\begin{array}{l}\text { Initiate pharmacotherapy for LDL cholesterol } \\
\text { level of } \geq 190 \mathrm{mg} \text { per deciliter or } \geq 160 \mathrm{mg} \text { per } \\
\text { deciliter with positive family history or } 2 \\
\text { additional risks }\end{array}$ & $\begin{array}{l}\text { Use new LDL cholesterol treatment cutoff point } \\
\text { of } \geq 130 \mathrm{mg} \text { per deciliter if diabetes mellitus } \\
\text { present }\end{array}$ \\
\hline
\end{tabular}

Notes: Copyright (c) 2008. Massachusetts Medical Society. All rights reserved. Reprinted with permission from de Ferranti S, Ludwig DS. Storm over statins-the controversy surrounding pharmacologic treatment of children. N Engl J Med. 2008;359(|3):| 309-| 3 | 2. ${ }^{30}$

Abbreviations: AAP, American Academy of Pediatrics; HDL, high-density lipoprotein; LDL, low-density lipoprotein; NCEP, National Cholesterol Education Program.

of this screen time limit is increased time available for activity. Studies support the view that screen time and weight and dysmetabolism are positively associated, ${ }^{37-39}$ but not all screen time is equally obesogenic..$^{40}$ Active screen time, for example, using interactive computerized sports and activities, so-called "exer-gaming", may feature in future exercise recommendations for children, given that exer-gaming can decrease the decline in activity levels during childhood. ${ }^{41}$ Exer-gaming has been the focus of several small RCTs, ${ }^{42-44}$ but in the future, we expect that it will be studied in far greater detail. In one of these studies, for example, children randomized to an exer-game intervention played fewer overall video games than controls, but more exer-games than controls, and had higher accelerometer-measured activity than controls..$^{41} \mathrm{~A}$ recent joint initiative has been launched between manufacturers of exer-games and the AHA to encourage activity in youth, and in adults,,$^{33}$ but the outcomes are not yet available. While current Canadian guidelines recommend at least 90 minutes per day of physical activity for all children ${ }^{45}$ in 2005, it was documented that up to $90 \%$ of children are not achieving these targets. ${ }^{46}$ Additionally, the AHA recommends exercise as part of its TLCs diet. ${ }^{33}$ Ongoing studies of the benefits of exercise to children are required. But pediatricians should include routine but tailored recommendations on simultaneous exercise and diet for all children, and these recommendations should be offered to the family, and to the child as a member of the family. 


\section{Therapeutic options: pharmacological agents Statins}

Statins are also known as 3-hydroxy-3-methylglutarylcoenzyme A (HMG-CoA) reductase inhibitors, so named as they act by inhibiting the enzyme HMG-CoA. While a full review of the cholesterol biosynthesis pathway is beyond the scope of this review, this enzyme is essential in the synthesis of cholesterol. Figure 1 describes graphically the steroid synthesis pathway, and indicates the numerous potential effects of inhibition of this pathway. ${ }^{30}$ Inhibition of the HMG-CoA enzyme by statins decreases LDLc by 2 mechanisms: it decreases de novo cholesterol synthesis; and simultaneously

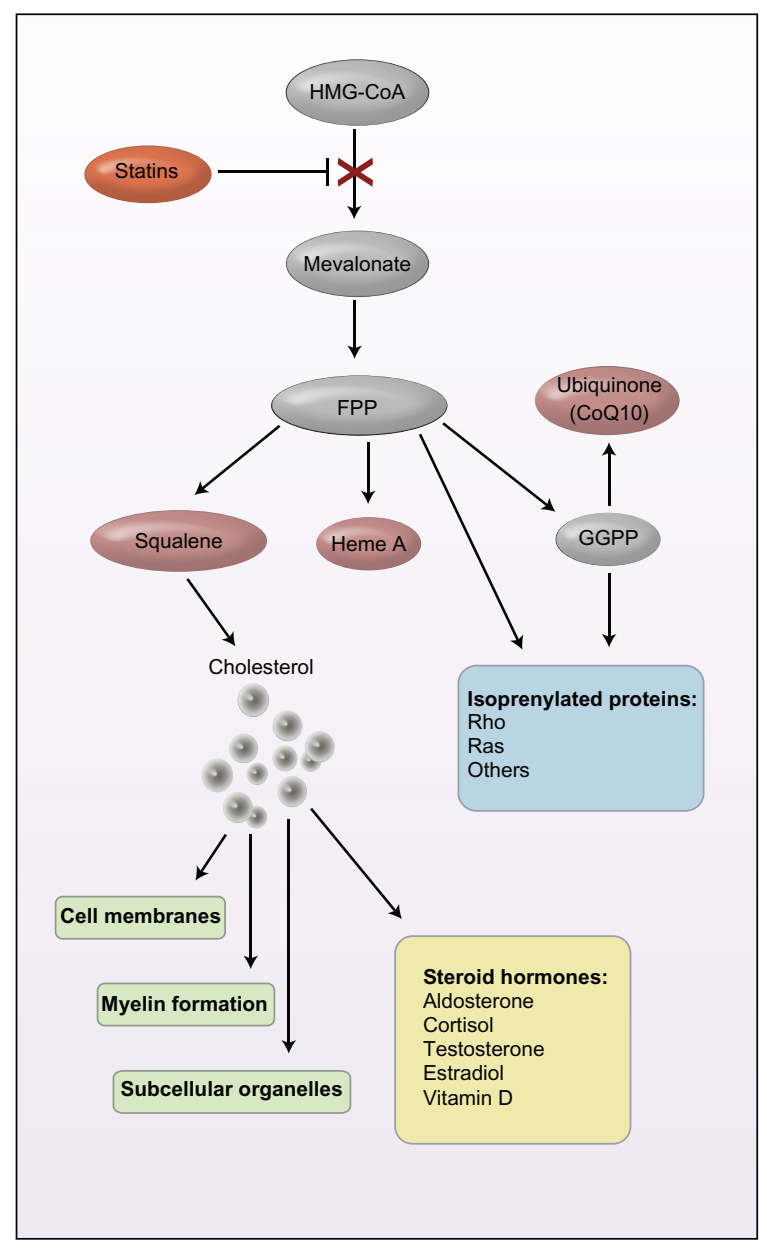

Figure I Steroid synthesis pathway. Inhibition of this steroid pathway by a statin (red) may have pleiotropic effects, influencing antioxidant activity (pink); intracellular processes (blue), including signal transduction, cell proliferation, and apoptosis; structural components (green); and steroid hormones (yellow). Arrows may reflect more than one enzyme reaction.

Copyright @ 2008 Massachusetts Medical Society. All rights reserved. Reproduced with permission from de Ferranti S, Ludwig DS. Storm over statins-the controversy surrounding pharmacologic treatment of children. N Engl J Med. 2008;359(13) $1309-1312 .^{30}$

Abbreviations: FPP, farnesyl pyrophosphate; GGPP, geranylgeranyl pyrophosphate; HMG-CoA, 3-hydroxy-methylglutaryl-coenzyme A. increases the synthesis of the LDL receptor by the liver, thus increasing clearance of LDLc.

The Food and Drug Administration (FDA) currently approves some statins for use in pediatric age range patients. Some statins are approved for children over 8 years of age, others only from 10 years of age. ${ }^{47}$ Approved statins include simvastatin, atorvastatin, pravastatin, fluvastatin, rosuvastatin, and lovastatin. However, maximum adult doses of statins are not approved in pediatric patients. All statins recommended by the FDA are approved for children with familial hypercholesterolemia, and some for other genetic or primary causes of dyslipidemia, depending on the populations in which the original studies were conducted. Data on cholesterol-lowering in other groups of children are deficient. Indications for (including the ages from which medications are approved) and the data to support cholesterol-lowering in pediatrics are extrapolated from either adult studies, or, for FDAapproved statins, extrapolated from studies of cholesterollowering in children with heFH. While it may be possible to extrapolate some data, there are other data that it may not be appropriate to extrapolate. For example, dietary changes are likely to be more beneficial to children with obesity and hypertriglyceridemia, or with other secondary causes of dyslipidemia, than to children with primary dyslipidemia. Therefore, perhaps, we should expect to use lower doses of pharmacological therapies for children with secondary dyslipidemia than for those with primary causes. But information on side-effect profiles is more likely to be similar in both groups. For more information on the statin controversies, 2 editorials present equally compelling arguments for therapy and for nonintervention. ${ }^{29,30}$ Notwithstanding the discussions, the AHA and the AAP both recommend statin therapy. ${ }^{19,22}$

The 2007 AHA scientific statement on drug therapy of high-risk lipid abnormalities in children and adolescents ${ }^{19}$ included significant changes compared with the 1998 position statement and compared with the NCEP II recommendations. ${ }^{48}$ Specifically, the 2007 AHA statement recommended the use of statin therapy for children with high-risk lipid abnormalities, and statin therapy had not previously been recommended. ${ }^{19}$ The 2007 statement also classified children with diabetes as high-risk, suggesting statin therapy at lower cholesterol levels. ${ }^{19}$ There were some caveats included in the 2007 statement. Firstly, caution should be exercised in adolescent females, as statins are contraindicated in pregnancy due to likely teratogenicity. A case series of FDA reports of potential teratogenicity following statin therapy analyzed 
52 live births, and identified 20 cases of structural defects, including central nervous system and limb abnormalities. ${ }^{49}$ Studies such as these must be interpreted in the context of mothers who required statin therapy, for example, for diabetes or dyslipidemia, and thus birth defects could potentially be attributable to their underlying pathologies rather than to statin use. Another cohort study of first trimester women taking statins, matched with first trimester women not taking statins has shown no difference in congenital anomalies between the offspring groups.$^{50}$ However, the women on statins were younger and their babies lighter than the matched controls, and these factors could confound the results. Until further studies are available, the consensus is that statins should not be prescribed to women of child-bearing age, without simultaneous prescription of contraception. One clinical approach to this, which might be worth considering in the pediatric population, would be recommending contraception simultaneously with initiation of statin therapy in sexually active female patients, and advising the patient regarding teratogenicity, and suggestions to stop statin therapy if pregnancy is suspected. It must be remembered that the oral contraceptive pill (OCP), one of the forms of contraception, is contraindicated in hypertriglyceridemia and may be pro-thrombotic in FH. So caution is required if considering initiating OCP therapy. A second caveat is that statin therapy should only be considered and initiated after a male pediatric patient has achieved pubertal development Tanner stage II or greater, or after menstruation in female pediatric patients, because statins act by interrupting cholesterol metabolism, and cholesterol is required for all pubertal sex steroid hormones. So there is, at least, a theoretical risk of statins interfering with puberty.

The AHA scientific statement recommends LDLc at which to consider starting therapy and therapeutic targets for statin-treated patients (See Table 2). ${ }^{19}$

Not all statins available in adult medicine are FDAapproved for pediatric age range patients. And the majority of data on which the FDA approvals are based, are data from studies of patients with familial hypercholesterolemia and other monogenic forms of hypercholesterolemia. Therefore,

Table 2 When to consider starting and therapeutic targets for statin therapy ${ }^{19}$

Consideration to starting therapy:

LDLc $>4.90 \mathrm{mmol} / \mathrm{L}(190 \mathrm{mg} / \mathrm{dL})$ or;

LDLc $>4.10 \mathrm{mmol} / \mathrm{L}(160 \mathrm{mg} / \mathrm{dL})$ and patient considered high risk.

Therapeutic targets after starting therapy:

LDLc $<3.35 \mathrm{mmol} / \mathrm{L}(130 \mathrm{mg} / \mathrm{dL})=$ minimal target;

LDLc $<2.85 \mathrm{mmol} / \mathrm{L}(110 \mathrm{mg} / \mathrm{dL})=$ ideal target. care should be exercised if the clinician chooses to apply knowledge acquired from the population of patients with familial hypercholesterolemia to a population of patients with an entirely different disease etiology, for example, obesity and secondary hypercholesterolemia. Also, the FDA approves only lower doses of statins for pediatric patients compared with approved doses for adult patients.

There are now several systematic reviews and metaanalyses $^{51-53}$ and a Cochrane Database meta-analysis on the effect of statins on cholesterol profile in children with heFH. ${ }^{54}$ No study identified an actual ischemic heart disease or vascular disease event in the patients studied during the study period. All of these statin studies demonstrate improved cholesterol profiles following statin therapy. For example, one of the more recent of these meta-analyses estimates that LDLc decreases by $1.60 \mathrm{mmol} / \mathrm{L}$ (62 mg/dL) (95\% confidence interval $[95 \% \mathrm{CI}] 1.40-1.80 \mathrm{mmol} / \mathrm{L}[54-70 \mathrm{mg} / \mathrm{dL}])$, HDLc increases by $0.20 \mathrm{mmol} / \mathrm{L}(7.8 \mathrm{mg} / \mathrm{dL})(95 \% \mathrm{CI}$ $0.03-0.38 \mathrm{mmol} / \mathrm{L}$ [1.2-14.7 mg/dL]), and total cholesterol decreases by $3.0 \mathrm{mmol} / \mathrm{L}(116 \mathrm{mg} / \mathrm{dL})(95 \% \mathrm{CI} 2.2-3.8 \mathrm{mmol} / \mathrm{L}$ [85.4-147.4 mg/dL]). ${ }^{51}$ Two of these systematic reviews also raise concerns about the inability to comment precisely on side-effect profiles, due to nonuniformity of trial reporting of and monitoring for side-effects, including interference with growth, nutrition, and puberty. ${ }^{51,53}$ Interestingly, 2 of these meta-analyses do report increased growth in the statintreated group compared with the placebo-treated group. ${ }^{51,53}$ This information on few patients over a maximum 2 years of growth is not a sufficient cause for concern at this stage, but requires further study. None of these studies identified a difference in the occurrence of myopathy or increased creatinine kinase between statin-treated and placebo-treated groups, but meta-analyses were not possible. ${ }^{51}$ Similarly, meta-analysis of liver transaminases was not possible. Although some of the individual studies did identify increased aspartate transferase and alanine transferase in the statin-treated groups, these increases were not statistically significant. ${ }^{51}$ Risk factors for myopathy have been derived from adult data; these risk factors include advanced age, female sex, low body mass index, diminished hepatic and renal function, multiple co-morbidities or medications, excess alcohol, intercurrent infections, surgery or trauma, drug interactions, and diet. Data from pediatric studies are scant, but clearly some of the risk factors above are less likely to occur in the general pediatric population, including advanced age, multiple co-morbidities, and multiple medications. Given that few pediatric studies have been undertaken, it is not possible to comment on the relative efficacy of one statin compared with another statin in pediatric patients, and 
Table 3 Recommendations for the use of HMG-CoA reductase inhibitors (statins) in children and adolescents with hyperlipidemia

\section{Patient Selection}

I. Begin with the present criteria of the expert panel of the NCEP for drug initiation.

2. The age and LDL level at which statin therapy is initiated may be influenced by the presence, magnitude, and number of other cardiovascular risk factors, as well as by the presence of cutaneous xanthomas.

3. Include the preferences of patient and family in the decision making.

4. In general, do not start before $10 \mathrm{yr}$ of age in boys and preferably after onset of menses in girls. Patients should ideally be at Tanner stage II or higher.

5. Ensure that there are no contraindications for statin therapy (eg, Important hepatic disease).

\section{Initiation and Titration}

I. The choice of the particular statin is a matter of preference.

2. Start with the lowest dose given once daily, usually at bedtime. Measure baseline CK, ALT, and AST.

3. Instruct the patient to report all potential adverse effects, especially myopathy (muscle cramps, weakness, asthenia, and more diffuse symptoms) immediately. If myopathy is present, its relation to recent physical activity should be assessed, the medication stopped, and CK assessed. The patient should be monitored for resolution of the myopathy and any associated increases in CK. Consideration can be given to restarting the medication once symptoms and laboratory abnormalities have resolved.

4. Advise female patients about concerns with regard to pregnancy and the need for appropriate contraception if warranted.

5. Advise about drug interactions, especially cyclosporine, fibric acid derivatives, niacin, erythromycin, azole antifungals, nefazadone and many HIV protease inhibitors.

6. After 4 wks, measure fasting lipoprotein profile, CK, ALT, and AST and compare with laboratory-specific reported normal values.

The threshold for worrisome CK is 10 times above the upper limit of reported normal; consider impact of physical activity.

The threshold for worrisome ALT or AST is 10 times above the upper limit of reported normal; consider impact of physical activity.

Target levels for LDL: minimal, $<3.35 \mathrm{mmol} / \mathrm{L}$ ( $130 \mathrm{mg} / \mathrm{dL}$ ); ideal, $<2.85 \mathrm{mmol} / \mathrm{L}$ (I $10 \mathrm{mg} / \mathrm{dL})$.

7. If target LDL levels are achieved and there are no laboratory abnormalities, continue therapy and recheck in 8 wk and then 3 mo.

8. If laboratory abnormalities are noted or symptoms are reported, temporarily withhold the drug and repeat blood work in approx. 2 wk. When the abnormalities return to normal, the drug may be restarted with close monitoring.

9. If target LDL levels are not achieved, double the dose, and repeat the blood work in 4 wk. Continue stepped titration up to the maximum recommended dose until target LDL levels are achieved or there is evidence of toxicity.

\section{Monitoring}

I. Monitor growth (height, weight and body mass index and relate to normal growth charts), sexual maturation, and development (Tanner staging).

2. Monitor fasting lipoprotein profile, CK, ALT, and AST every 3 to 6 mo.

3. Monitor and encourage compliance with lipid-lowering dietary and drug therapy. Serially assess and counsel for other risk factors, such as weight gain, smoking, and inactivity.

4. Counsel adolescent females about statin contraindications in pregnancy and the need for abstinence or use of appropriate contraceptive measures. Seek referral to an adolescent medicine or gynecologic specialist as appropriate.

Copyright ( 2007 American Heart Association, Inc. Reprinted with permission from McCrindle BW, Urbina EM, Dennison BA, Jacobson MS, Steinberger J, Rocchini AP, et al. Drug therapy of high-risk lipid abnormalities in children and adolescents: a scientific statement from the American Heart Association Atherosclerosis, Hypertension, and Obesity in Youth Committee, Council of Cardiovascular Disease in the Young, with the Council on Cardiovascular Nursing. Circulation. 2007;1 I5 (14):1948-1967.19

Abbreviations: CK, creatine kinase; ALT, alanine aminotransferase; AST, aspartate aminotransferase; LDL, low-density lipoprotein; HMG-CoA, 3-hydroxy-methylglutarylcoenzyme A; NCEP, National Cholesterol Education Program.

this prevents the possibility of recommending a specific statin. Extrapolation from adult data may help, but further pediatric studies are required.

The AHA scientific statement gives very specific guidelines on initiating and monitoring response to therapy with statins. These are summarized in Table 3, which has been reproduced from the AHA scientific statement. The AHA scientific statement gives exhaustive information on the background to these guidelines. ${ }^{19}$

Type 1 diabetes mellitus is one of the defined high-risk conditions in the AHA position statement. ${ }^{19}$ A large multicenter RCT is ongoing, evaluating the potential risks and benefits of starting statin therapy in young pediatric patients with type 1 diabetes mellitus. ${ }^{55}$ When considering the argument for and against statin use in pediatrics, and using children with diabetes as an example, once these children are transitioned from pediatric clinics to adolescent or young adult clinics, they may be started on statin therapy, and the indications for this are largely based on adult studies. While there are clear differences between children and adults, the differences between adolescents, especially pubertal or postpubertal adolescents, and adults are much less clear-cut. If the older child, in a pediatric clinic, is postpubertal, and is counseled on the risks of teratogenicity and therefore started on OCP or another form of contraception and a statin, is there really a difference between the adolescent in a pediatric clinic and the adolescent in an adult clinic? Perhaps pediatricians are justified in their cautious approach to starting statins in young children, but in older adolescents, who are pubertal, perhaps this caution is not equally justified. As with all therapies 
initiated in pediatric populations, this should be discussed with the child and the parents, and their concerns taken into consideration.

\section{Ezetimibe}

Ezetimibe selectively inhibits absorption of cholesterol at the small intestinal brush border. In selectively inhibiting cholesterol absorption, ezetimibe does not inhibit absorption of TG or fat-soluble vitamins. The cholesterol-lowering effectiveness of ezetimibe has been documented in several trials, in several groups of patients, including those with hoFH, ${ }^{56}$ polygenic hypercholesterolemia, ${ }^{57}$ heFH,${ }^{57}$ and familial combined hyperlipidemia. ${ }^{58}$ In each of these studies, ezetimibe appeared to be very well tolerated, with no identified problems with growth or pubertal development.

These studies show clearly the effectiveness of ezetimibe in reducing cholesterol, without significant side-effects identified. However, the problem, previously discussed, about cholesterol-lowering efficacy being distinct from reduction in cardiovascular risk, cardioprotection, and reduction in end-points of vascular and cardiovascular disease, is again emphasized by recent studies on ezetimibe. A recent study, Effect of Combination Ezetimibe and High-Dose Simvastatin versus Simvastatin alone on the Atherosclerotic Process in Patients with Heterozygous Familial Hypercholesterolemia, demonstrated no improvement in CIMT with combined simvastatin and ezetimibe therapy, and no increase in HDLc with ezetimibe therapy. ${ }^{59}$ However, the results of this study are difficult to apply to other populations of patients, as only patients with normal CIMT were selected for inclusion in this study. A further study, Simvastatin and Ezetimibe in Aortic Stenosis trial, identified higher cancer incidence and higher rates of death from cancer over a 4-year period in adult patients treated with ezetimibe than those treated with simvastatin $(9.9 \%$ vs $7.0 \%, P=0.03$ and $4.1 \%$ vs $2.5 \%, P=0.05$, respectively). ${ }^{60}$ The analyses did not reveal an increase in any specific cancer, or any change in cancer incidence with duration of statin therapy. We do not know of any similar reports of malignancies in children treated with ezetimibe. Care needs to be exercised when extrapolating these results to pediatrics, as malignancies are more common in adults than in children, and furthermore, malignancies are more likely to be identified sooner in adult patients enrolled in trials than in those not enrolled in trials. Nonetheless, the results of this study carry a warning to clinicians. The results of these 2 trials are disappointing in light of other studies. An ongoing large, multicenter trial, Improved Reduction of Outcomes: Vytorin Efficacy
International Trial (IMPROVED-IT), which aims to compare the cardioprotection of simvastatin alone and combined simvastatin with ezetimibe, may help to resolve the discrepancies between these studies to date. ${ }^{61}$ However, we agree with other authors, who have called for further studies examining specifically the effectiveness and side-effects in pediatric patients. ${ }^{51,62}$ We think that these future studies should take the form of either large multicenter RCTs, databases, or both, to record the progress of all patients treated with ezetimibe. We also suggest that future studies should aim to standardize the cholesterol, endocrine, metabolic, and vascular function outcomes being recorded, as well as recording any potential development of malignancies on therapy.

\section{Bile acid resins}

While bile acid resins were one of the first pharmacological therapies used in hypercholesterolemia, their use has been supplanted by newer pharmaceutical agents, largely due to the frequency and severity of gastrointestinal side-effects (primarily abdominal pain and nausea). Bile acid resins include colestipol and cholestyramine. They act by binding to intestinal bile acids, preventing the reabsorption and recirculation of bile acids, resulting in intestinal excretion of bile salts, with a consequent increase in conversion of cholesterol to bile salts. There is a consequent reduction in hepatic cholesterol, an increase in LDL receptors, and an overall reduction in the circulating cholesterol pool. Cholestyramine was studied in a landmark RCT in 1984, and was found to reduce cholesterol by $8.5 \%$, compared with placebo. ${ }^{63}$ Furthermore, an observational subanalysis of the cholestyramine-treated group showed a dose-dependent relationship between the amount of cholesterol reduction achieved and the reduction in risk of coronary heart disease ${ }^{64}$ However, due to side-effects and lack of tolerability, as well as the use of new alternatives, these drugs fell into disuse.

However, colesevelam hydrochloride, a newer bile acid resin, was recently trialed in children with heFH. ${ }^{65}$ Colesevelam was given either alone or in combination with a statin. Colesevelam resulted in decreased LDLc and compliance was good, with few complaints of side-effects. Following this trial, various authors expect that interest in bile acid resins will increase. ${ }^{24}$ Furthermore, colesevelam is FDA approved for lowering $\mathrm{HbA}_{1 \mathrm{c}}$ and may be valuable for use in patients with diabetes. Of particular note, FDA approval for pediatric use of bile acid resins was never achieved. However, potential future studies, if they produce results similar to Stein's recent trial, ${ }^{65}$ may result in approval in the future. 


\section{Niacin and fibrates}

Niacin is a hydrophilic B complex vitamin, which increases HDLc levels and reduces very low-density lipoprotein cholesterol (VLDLc) levels, by reducing production and release of VLDLc by the liver. Niacin is sometimes prescribed for pediatric patients with hoFH, a condition which is associated with symptomatic ischemic heart and vascular disease at very young ages ${ }^{66}$ Niacin may also be prescribed for patients with increased lipoprotein A and a history of cerebrovascular accidents. ${ }^{66}$ Niacin is not commonly used in pediatric patients with other conditions or other causes of hypercholesterolemia, and data on its efficacy are limited. Known potential side-effects of niacin include flushing, impaired glucose tolerance, liver failure, and myopathy.

Fibrates and fenofibric acid (fenofibrate) derivatives act on lipid metabolism by activating the peroxisome proliferator-activated receptor-alpha (PPAR- $\alpha$ ) and act on the metabolism of TG and HDLc through several pathways including: reducing plasma TG levels by inhibiting their synthesis and stimulating their clearance; decreasing both apo C II and apo C III expression in the liver via PPAR- $\alpha$ activation, and thus delaying the catabolism of TG; and increasing HDLc levels by increasing hepatic apo A I and II synthesis.

Fibrates have been the primary pharmacologic agent to target primary hypertriglyceridemia. ${ }^{19,67}$ The efficacy and safety of fibrates in the children population have been demonstrated, ${ }^{68}$ but additional pediatric studies suggest that these drugs may be unable to decrease TG levels sufficiently. ${ }^{69}$ One group of authors has suggested an incremental approach to pharmaceutical treatment of pediatric hypertriglyceridemia: 1) Use of 3 fatty acids or medium-chain TG; 2) Addition of a cholesterol-lowering medication; 3) Use of fibrates if this combination fails to reduce $\mathrm{TG}^{70}$

\section{Final statement on pharmacological therapy}

Currently, statins are the recommended first-line pharmacological therapy for children with hyperlipidemia, in whom sufficient diet and lifestyle modifications have not sufficiently reduced cholesterol measures. Ongoing studies are examining other pharmacological therapies, both as monotherapies and in combination with other therapies including statins. We do not know what the future holds, in terms of future reviews of current recommendations. But clinicians who prescribe statins should be aware of the potential and debated side-effects, and should monitor closely for these, and for unsuspected side-effects. At all times, and with all therapies, the patient and parents must be supported and encouraged to make continuous diet and lifestyle modifications.

\section{Future directions}

The ongoing debates about statins or other therapy for children and adolescents are healthy debates, and should continue, until such time as large multicenter databases and RCTs address the issues of efficacy and safety of statins and other cholesterol-lowering therapy in children. However, when faced with an individual patient, therapy should be individualized to that patient, and should, therefore, address risk and benefit profiles in that individual patient. If therapy is initiated, regular follow-up with monitoring of cholesterol levels, side-effects, and growth, nutrition, and puberty are essential. It is the duty of the clinician, as well as parents and society at large, to ensure that the child's or adolescent's therapy includes ongoing dietary and lifestyle intervention and monitoring, even and especially after starting pharmacological therapy. Finally, if one of the outcomes of the debate on statins and other cholesterol-lowering therapies in children and adolescents is modification of environmental and societal diet and lifestyle, then future generations of children, and adults, can only benefit. Large multicenter RCTs and databases for children on statins and other cholesterol-lowering therapies should be initiated, so that information on children attending all pediatric centers, large and small, can be entered and recorded to inform future studies and policies. Policy-makers can be lobbied, and if persuaded that interventions in childhood may modify diseases in adulthood, then governmental or federal funding may be made available. Funding from pharmaceutical industry, if available, should be used only if the funding is ethical and independent of any influences on study design or outcomes (indications for prescription and choice of medications recommended, etc). Consideration of screening is important, and should be instituted whether targeted or universal. This might be conducted simultaneously with vaccination or adolescent health assessments, dependent on local policies for medical examination of healthy children and adolescents. However, consensus needs to be achieved by all parties, on the indications for and benefits of interventions for dyslipidemia in childhood. For this to be achieved, ongoing pediatric studies are required.

\section{Summary}

There is significant evidence that atherosclerosis has its origins in childhood. While medications have proven benefit 
in cholesterol reduction in children and adolescents, there have not been sufficient data proving benefit in improvement in endothelial function, or other improvements in cardiovascular end-points. This is a problem germane to diseases that begin in childhood, but manifest disease only in adulthood, meaning that only surrogate markers of disease are amenable to pediatric studies. Large multicenter databases, RCTs, and long-term epidemiological studies following treated and untreated children into adulthood, should help to address the remaining questions. In the interim, the $\mathrm{AHA}^{19}$ and the $\mathrm{AAP}^{22}$ have endorsed statin therapy as first-line therapy for pediatric hyperlipidemia, after sufficient diet and lifestyle changes have been effected, in children of 8 years and older, who have entered Tanner II puberty (for males) and have had menarche (for females). The FDA has approved the use of statins for children of 8 to 10 years and older with heFH. There is no incontrovertible evidence of impaired growth, pubertal development, or cognitive development with statin therapy to date. Statins are potentially teratogenic, thus requiring extra caution, and perhaps consideration of simultaneous prescribing of the oral contraceptive pill in females of child-bearing years. Finally, pharmacological therapy should not be prescribed without taking every opportunity to continuously encourage adherence to healthy diet and lifestyle choices. We encourage caution in clinicians who are considering prescribing statin therapy, and we urge that parents and patients be appraised fully of the risks and the current debates on this topic.

It appears that RL Holman was correct: atherosclerosis is "a pediatric problem". The recent additional information is that the identification of the correct therapy in pediatrics is also "a pediatric problem" - and the ideal solution to the problem remains to be identified and agreed upon by all concerned pediatricians. ${ }^{1}$

\section{Abbreviations}

AHA, American Heart Association; AAP, American Academy of Pediatrics; CIMT, carotid intima media thickness; FDA, Food and Drug Administration; HDLc, high-density lipoprotein cholesterol; heFH, heterozygous familial hypercholesterolemia; HMG-CoA, 3-hydroxy-3-methylglutaryl-coenzyme A; hoFH, homozygous familial hypercholesterolemia; LDLc, low-density lipoprotein cholesterol; NCEP, National Cholesterol Education Program; OCP, oral contraceptive pill; P-Day, Pathobiological Determinants of Atherosclerosis in Youth Study; RCT, randomized controlled clinical trial; TC, total cholesterol; TG, triglycerides; TLCs, therapeutic lifestyle changes.

\section{Disclosure}

The authors report no conflicts of interest in this work.

\section{References}

1. Holman RL. Atherosclerosis-a pediatric nutrition problem? Am J Clin Nutr. 1961;9:565-569.

2. Relationship of atherosclerosis in young men to serum lipoprotein cholesterol concentrations and smoking. A preliminary report from the Pathobiological Determinants of Atherosclerosis in Youth (PDAY) Research Group. JAMA. 1990;264(23):3018-3024.

3. McGill HC Jr, McMahan CA, Zieske AW, Malcom GT, Tracy RE, Strong JP. Effects of nonlipid risk factors on atherosclerosis in youth with a favorable lipoprotein profile. Circulation. 2001;103(11):1546-1550.

4. Enos WF, Holmes RH, Beyer J. Coronary disease among United States soldiers killed in action in Korea; preliminary report. JAMA. 1953;152(12):1090-1093

5. McNamara JJ, Molot MA, Stremple JF, Cutting RT. Coronary artery disease in combat casualties in Vietnam. JAMA. 1971;216(7):1185-1187.

6. Newman WP 3rd, Freedman DS, Voors AW, Gard PD, Srinivasan SR, Cresanta JL, et al. Relation of serum lipoprotein levels and systolic blood pressure to early atherosclerosis. The Bogalusa Heart Study. $N$ Engl J Med. 1986;314(3):138-144.

7. Berenson GS, Srinivasan SR, Bao W, Newman WP 3rd, Tracy RE, Wattigney WA. Association between multiple cardiovascular risk factors and atherosclerosis in children and young adults. The Bogalusa Heart Study. N Engl J Med. 1998;338(23):1650-1656.

8. Davis PH, Dawson JD, Riley WA, Lauer RM. Carotid intimal-medial thickness is related to cardiovascular risk factors measured from childhood through middle age: The Muscatine Study. Circulation. 2001; 104(23):2815-2819.

9. Knoflach M, Kiechl S, Kind M, Said M, Sief R, Gisinger M, et al. Cardiovascular risk factors and atherosclerosis in young males: ARMY study (Atherosclerosis Risk-Factors in Male Youngsters). Circulation. 2003;108(9):1064-1069.

10. Aggoun Y, Bonnet D, Sidi D, Girardet JP, Brucker E, Polak M, et al. Arterial mechanical changes in children with familial hypercholesterolemia. Arterioscler Thromb Vasc Biol. 2000;20(9):2070-2075.

11. Treiber F, Papavassiliou D, Gutin B, Malpass D, Yi W, Islam S, et al. Determinants of endothelium-dependent femoral artery vasodilation in youth. Psychosom Med. 1997;59(4):376-381.

12. Tounian P, Aggoun Y, Dubern B, Varille V, Guy-Grand B, Sidi D, et al. Presence of increased stiffness of the common carotid artery and endothelial dysfunction in severely obese children: a prospective study. Lancet. 2001;358(9291):1400-1404.

13. Mahmud FH, Hill DJ, Cuerden MS, Clarson CL. Impaired vascular function in obese adolescents with insulin resistance. J Pediatr. 2009;155(5):678-682.

14. Newkumet KM, Goble MM, Young RB, Kaplowitz PB, Schieken RM. Altered blood pressure reactivity in adolescent diabetics. Pediatrics. 1994;93(4):616-621.

15. Mahmud FH, van Uum S, Kanji N, Thiessen-Philbrook H, Clarson CL. Impaired endothelial function in adolescents with type 1 diabetes mellitus. J Pediatr. 2008;152(4):557-562.

16. Heilman K, Zilmer M, Zilmer K, Lintrop M, Kampus P, Kals J, et al. Arterial stiffness, carotid artery intima-media thickness and plasma myeloperoxidase level in children with type 1 diabetes. Diabetes Res Clin Pract. 2009;84(2):168-173.

17. McMahan CA, Gidding SS, Fayad ZA, Zieske AW, Malcom GT, Tracy RE, et al. Risk scores predict atherosclerotic lesions in young people. Arch Intern Med. 2005;165(8):883-890.

18. Zeitler P, Epstein L, Grey M, Hirst K, Kaufman F, Tamborlane W, et al. Treatment options for type 2 diabetes in adolescents and youth: a study of the comparative efficacy of metformin alone or in combination with rosiglitazone or lifestyle intervention in adolescents with type 2 diabetes. Pediatr Diabetes. 2007;8(2):74-87. 
19. McCrindle BW, Urbina EM, Dennison BA, Jacobson MS, Steinberger J, Rocchini AP, et al. Drug therapy of high-risk lipid abnormalities in children and adolescents: a scientific statement from the American Heart Association Atherosclerosis, Hypertension, and Obesity in Youth Committee, Council of Cardiovascular Disease in the Young, with the Council on Cardiovascular Nursing. Circulation. 2007;115(14): 1948-1967.

20. Wiegman A, Hutten BA, de Groot E, Rodenburg J, Bakker HD, Buller HR, et al. Efficacy and safety of statin therapy in children with familial hypercholesterolemia: a randomized controlled trial. JAMA. 2004;292(3):331-337.

21. de Jongh S, Lilien MR, op't Roodt J, Stroes ES, Bakker HD, Kastelein JJ. Early statin therapy restores endothelial function in children with familial hypercholesterolemia. J Am Coll Cardiol. 2002;40(12):2117-2121.

22. Daniels SR, Greer FR. Lipid screening and cardiovascular health in childhood. Pediatrics. 2008;122(1):198-208.

23. Rahalkar AR, Hegele RA. Monogenic pediatric dyslipidemias: classification, genetics and clinical spectrum. Mol Genet Metab. 2008; 93(3):282-294.

24. Lughetti L, Bruzzi P, Predieri B. Evaluation and management of hyperlipidemia in children and adolescents. Curr Opin Pediatr. 2010;22:485-493.

25. Ford ES, Li C, Zhao G, Mokdad AH. Concentrations of lowdensity lipoprotein cholesterol and total cholesterol among children and adolescents in the United States. Circulation. 2009;119(8): 1108-1115.

26. American Academy of Pediatrics. Committee on Nutrition. Cholesterol in childhood. Pediatrics. 1998;101(1 Pt 1):141-147.

27. O'Grady MJ, Brown AM, O’Neill MB. Cholesterol screening in an at-risk pediatric population. Pediatr Cardiol. 2008;29(3):609-613.

28. Ritchie SK, Murphy EC, Ice C, Cottrell LA, Minor V, Elliott E, et al. Universal versus targeted blood cholesterol screening among youth: The CARDIAC project. Pediatrics. 126(2):260-265.

29. Stein EA. Statins and children: whom do we treat and when? Circulation. 2007;116(6):594-595.

30. de Ferranti S, Ludwig DS. Storm over statins-the controversy surrounding pharmacologic treatment of children. NEngl J Med.2008; 359(13):1309-1312.

31. Gidding SS, Dennison BA, Birch LL, Daniels SR, Gillman MW, Lichtenstein AH, et al. Dietary recommendations for children and adolescents: a guide for practitioners: consensus statement from the American Heart Association. Circulation. 2005;112(13): 2061-2075.

32. Gidding SS, Dennison BA, Birch LL, Daniels SR, Gillman MW, Lichtenstein $\mathrm{AH}$, et al. Dietary recommendations for children and adolescents: a guide for practitioners. Pediatrics. 2006;117(2): 544-559.

33. American Heart Association. [2010 Aug 10]; Available from: www. americanheart.org.

34. Shafiq N, Singh M, Kaur S, Khosla P, Malhotra S. Dietary treatment for familial hypercholesterolaemia. Cochrane Database Syst Rev. (1):CD001918.

35. Wells GD, Noseworthy MD, Hamilton J, Tarnopolski M, Tein I. Skeletal muscle metabolic dysfunction in obesity and metabolic syndrome. Can J Neurol Sci. 2008;35(1):31-40.

36. Krebs NF, Himes JH, Jacobson D, Nicklas TA, Guilday P, Styne D. Assessment of child and adolescent overweight and obesity. Pediatrics. 2007;120 Suppl 4:S193-S228.

37. Roblin L. Childhood obesity: food, nutrient, and eating-habit trends and influences. Appl Physiol Nutr Metab. 2007;32(4):635-645.

38. Mark AE, Janssen I. Relationship between screen time and metabolic syndrome in adolescents. J Public Health (Oxf). 2008;30(2):153-160.

39. Hardy LL, Denney-Wilson E, Thrift AP, Okely AD, Baur LA. Screen time and metabolic risk factors among adolescents. Arch Pediatr Adolesc Med. 164(7):643-649.
40. Martinez-Gomez D, Tucker J, Heelan KA, Welk GJ, Eisenmann JC. Associations between sedentary behavior and blood pressure in young children. Arch Pediatr Adolesc Med. 2009;163(8): 724-730.

41. Spanakis E, Gragnoli C. Bariatric surgery, safety and type 2 diabetes. Obes Surg. 2009;19(3):363-368.

42. Chin A, Paw MJ, Jacobs WM, Vaessen EP, Titze S, van Mechelen W. The motivation of children to play an active video game. J Sci Med Sport. 2008;11(2):163-166.

43. Madsen KA, Yen S, Wlasiuk L, Newman TB, Lustig R. Feasibility of a dance videogame to promote weight loss among overweight children and adolescents. Arch Pediatr Adolesc Med. 2007;161(1):105-107.

44. Ni Mhurchu C, Maddison R, Jiang Y, Jull A, Prapavessis H, Rodgers A. Couch potatoes to jumping beans: A pilot study of the effect of active video games on physical activity in children. Int J Behav Nutr Phys Act. 2008;5:8.

45. Cameron C, Craig CL, Bull FC, Bauman A. Canada's physical activity guides: has their release had an impact? Can J Public Health. 2007; 98 Suppl 2:S161-S169.

46. Belanger M, Gray-Donald K, O’Loughlin J, Paradis G, Hanley J. When adolescents drop the ball: sustainability of physical activity in youth. Am J Prev Med. 2009;37(1):41-49.

47. Federal Drugs Authority. [2010 Aug 12]; Available from: www.fda.gov

48. National Cholesterol Education Program (NCEP): highlights of the report of the Expert Panel on Blood Cholesterol Levels in Children and Adolescents. Pediatrics. 1992;89(3):495-501.

49. Kusters DM, Homsma SJ, Hutten BA, Twickler MT, Avis HJ, der Post JA, et al. Dilemmas in treatment of women with familial hypercholesterolaemia during pregnancy. Neth J Med. 68(1):299-303.

50. Taguchi N, Rubin ET, Hosokawa A, Choi J, Ying AY, Moretti ME, et al. Prenatal exposure to HMG-CoA reductase inhibitors: effects on fetal and neonatal outcomes. Reprod Toxicol. 2008;26(2):175-177.

51. O'Gorman CS, Higgins MF, O'Neill MB. Systematic review and metaanalysis of statins for heterozygous familial hypercholesterolemia in children: evaluation of cholesterol changes and side effects. Pediatr Cardiol. 2009;30(4):482-489.

52. Avis HJ, Vissers MN, Stein EA, Wijburg FA, Trip MD, Kastelein JJ, et al. A systematic review and meta-analysis of statin therapy in children with familial hypercholesterolemia. Arterioscler Thromb Vasc Biol. 2007;27(8):1803-1810.

53. Arambepola C, Farmer AJ, Perera R, Neil HA. Statin treatment for children and adolescents with heterozygous familial hypercholesterolaemia: a systematic review and meta-analysis. Atherosclerosis. 2007;195(2):339-347.

54. Vuorio A, Kuoppala J, Kovanen PT, Humphries SE, Strandberg T, Tonstad S, et al. Statins for children with familial hypercholesterolemia. Cochrane Database Syst Rev. 7:CD006401.

55. Adolescent type 1 Diabetes Cardio-renal Intervention Trial (AdDIT). BMC Pediatr. 2009;9:79.

56. Gagne C, Gaudet D, Bruckert E. Efficacy and safety of ezetimibe coadministered with atorvastatin or simvastatin in patients with homozygous familial hypercholesterolemia. Circulation. 2002;105(21): 2469-2475.

57. Yeste D, Chacon P, Clemente M, Albisu MA, Gussinye M, Carrascosa A. Ezetimibe as monotherapy in the treatment of hypercholesterolemia in children and adolescents. J Pediatr Endocrinol Metab. 2009;22(6):487-492.

58. Clauss S, Wai KM, Kavey RE, Kuehl K. Ezetimibe treatment of pediatric patients with hypercholesterolemia. J Pediatr. 2009;154(6): 869-872.

59. Kastelein JJ, Akdim F, Stroes ES, Zwinderman AH, Bots ML, Stalenhoef AF, et al. Simvastatin with or without ezetimibe in familial hypercholesterolemia. N Engl J Med. 2008;358(14):1431-1443.

60. Rossebo AB, Pedersen TR, Boman K, Brudi P, Chambers JB, Egstrup K, et al. Intensive lipid lowering with simvastatin and ezetimibe in aortic stenosis. N Engl J Med. 2008;359(13):1343-1356. 
61. Califf RM, Lokhnygina Y, Cannon CP, Stepanavage ME, McCabe CH, Musliner TA, et al. An update on the IMProved reduction of outcomes: Vytorin Efficacy International Trial (IMPROVE-IT) design. Am Heart J. 159(5):705-709.

62. Lughetti L. Drugs for children with hypercholesterolemia: be cautious. $J$ Pediatr Endocrinol Metab. 2009;22(6):483-485.

63. The Lipid Research Clinics Coronary Primary Prevention Trial results. I. Reduction in incidence of coronary heart disease. JAMA. 1984;251(3):351-364.

64. The Lipid Research Clinics Coronary Primary Prevention Trial results. II. The relationship of reduction in incidence of coronary heart disease to cholesterol lowering. JAMA. 1984;251(3):365-374.

65. Stein EA, Marais AD, Szamosi T, Raal FJ, Schurr D, Urbina EM, et al. Colesevelam hydrochloride: efficacy and safety in pediatric subjects with heterozygous familial hypercholesterolemia. J Pediatr. 156(2):231-236, e231-233.
66. Kalra S, Gandhi A, Kalra B, Agrawal N. Management of dyslipidemia in children. Diabetol Metab Syndr. 2009;1(1):26.

67. McCrindle BW. Screening and management of hyperlipidemia in children. Pediatr Ann. 2000;29(8):500-508.

68. Wheeler KA, West RJ, Lloyd JK, Barley J. Double blind trial of bezafibrate in familial hypercholesterolaemia. Arch Dis Child. 1985;60(1): 34-37.

69. Ginsberg HN. Hypertriglyceridemia: new insights and new approaches to pharmacologic therapy. Am J Cardiol. 2001;87(10):1174-1180, A1174.

70. Manlhiot C, Larsson P, Gurofsky RC, Smith RW, Fillingham C, Clarizia NA, et al. Spectrum and management of hypertriglyceridemia among children in clinical practice. Pediatrics. 2009;123(2): 458-465.
Vascular Health and Risk Management

\section{Publish your work in this journal}

Vascular Health and Risk Management is an international, peerreviewed journal of therapeutics and risk management, focusing on concise rapid reporting of clinical studies on the processes involved in the maintenance of vascular health; the monitoring, prevention and treatment of vascular disease and its sequelae; and the involvement of

\section{Dovepress}

metabolic disorders, particularly diabetes. This journal is indexed on PubMed Central and MedLine. The manuscript management system is completely online and includes a very quick and fair peer-review system, which is all easy to use. Visit http://www.dovepress.com/ testimonials.php to read real quotes from published authors. 